\title{
How to interpret urine toxicology tests
}

\section{Emma M Dyer, ${ }^{1}$ Sormeh Salehian ${ }^{2}$}

\begin{abstract}
${ }^{1}$ Evelina London Children's Healthcare, London, UK

${ }^{2}$ Paediatric Department, Addenbrooke's Hospital, Cambridge, UK
\end{abstract}

\section{Correspondence to} Dr Emma M Dyer, Evelina London Children's Healthcare, London, UK; emma.m.dyer@ gmail.com

Accepted 21 February 2019 Published Online First 26 March 2019

\section{Check for updates}

(c) Author(s) (or their employer(s)) 2020. No commercial re-use. See rights and permissions. Published by BMJ.

To cite: Dyer EM, Salehian S. Arch Dis Child Educ Pract Ed 2020;105:84-88.

\begin{abstract}
A 13-year-old girl presents to the emergency department for the second time with an unresponsive episode. She has a GCS (Glasgow Coma Scale) score of 11 on arrival and all other observations are normal. The story is unclear, but there are ongoing safeguarding concerns and the family are known to social services. All investigations are normal. After a period of observation on the ward, her GCS returns to normal and she appears well. Both on the first presentation and this presentation ingestion of a toxin was suspected. However, this was denied by the patient and urine toxicology screen was negative. Does this rule out toxin ingestion? Will this change your management?
\end{abstract}

\section{INTRODUCTION}

The paediatric population are exposed to toxins more than any other age group. In the USA in 2016, 60\% of all exposures were in the paediatric population and $1.6 \%$ of all children had a reported exposure to a toxin. Seventy-seven per cent of paediatric exposures were in children aged $<6$ years. ${ }^{1}$

Most cases of toxin exposure in the under $12 \mathrm{~s}$ are accidental, whereas the teenage population tend to have intentional exposures. ${ }^{2}$ The adolescent group carry higher rates of morbidity and mortality following exposure. Of all toxin-related fatalities, $73 \%$ of the total fatalities (across children and adults) were in the paediatric population, with $42 \%$ being in the 12-19 age group. ${ }^{1}$

Clearly, toxin exposure in paediatric patients is an important and serious presentation. However, detecting the toxin involved can be difficult, and toxin screening as a diagnostic tool is controversial, poorly understood and consensus on how it should be used is lacking.

Qualitative urine toxicology screens are relatively low cost and straightforward tests, and many are requested by paediatricians every day. The use of this test is significantly increasing, but there is often a lack of clarity regarding interpretation ofthe results. ${ }^{3}$

\section{PHYSIOLOGICAL BACKGROUND AND TECHNICAL BACKGROUND}

A urine toxicology screen is a qualitative test of specific drugs or their metabolites in the urine. ${ }^{2}$ Substances are detected in the urine by enzymatic immunoassays (EIAs). However, many of these lack specificity and/or sensitivity, and they are limited to drugs that reach detectable concentrations in the urine. ${ }^{3}$

With an immunoassay, an antibody binds to a specific part of a molecule's structure as shown in figure 1 . This causes problems as many drugs and toxins share similar structures, and conversely within the same class of drugs, compounds may have quite differing structures. ${ }^{3}$

Urine collection pads in younger children, are an accurate way to take urine toxicology samples and so this test is relatively straight forward to perform even in younger children without bladder control. $^{4}$

\section{INDICATIONS/LIMITATIONS}

\section{Interpreting a urine toxicology test}

The sensitivity and specificity of urine toxicology screens vary depending on which toxin you are detecting. The EIAs may be able to detect one drug in a particular class, but not others. Table 1 outlines the main classes of drugs tested for on a urine toxicology screen including what will be picked up and what it may miss.

In addition to these toxins, there are other classes that would not be picked up at all by a routine screen, but may still be of interest, as seen in box 1 .

The presence of drugs at a detectable level in the urine is generally short lived, although metabolites may be present for longer. ${ }^{2}$ Different substances remain in the urine for different lengths of time after ingestion, and this influences interpretation. Table 2 demonstrates the 


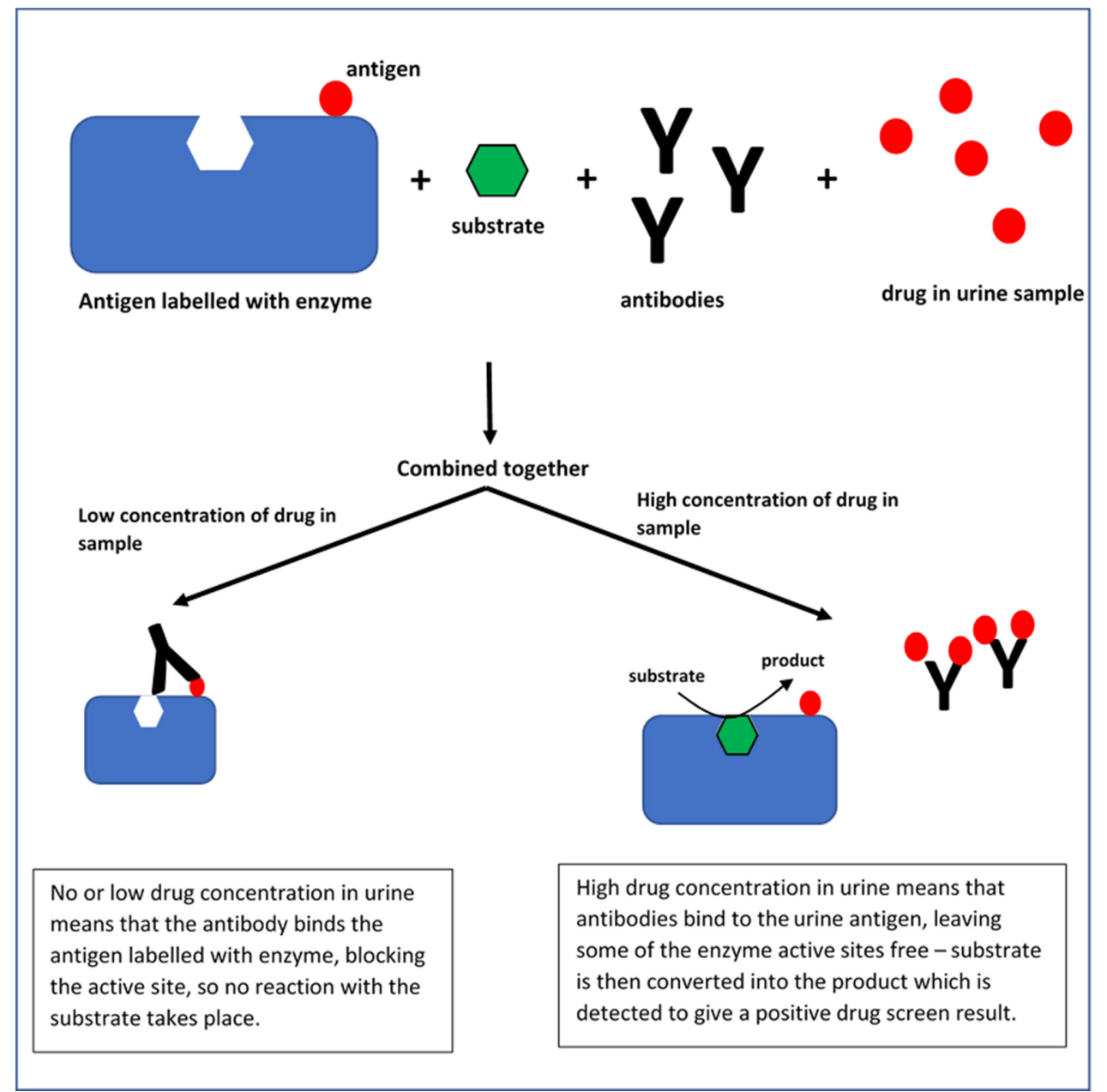

Figure 1 Enzyme immunoassay in urine toxicology screen—a commonly used technique.

timelines for detection of some of the more common substances. ${ }^{3}$

Any positive test should ideally be sent for confirmatory testing, the gold standard being gas chromatography or mass spectrometry. This is time-consuming and expensive and may not be widely available. Even this may still fail to detect certain substances. ${ }^{3}$

A positive test may suggest exposure to a substance, however that does not mean that the signs or symptoms demonstrated are attributable to that substance. There is a danger that with a positive screen other diagnoses may be missed, and it is important to remember that a urine toxicology screen is not a diagnostic test. ${ }^{23}$

A negative test tells you that the substance was not present at the time of testing at the minimum threshold quantity for detection, but cannot rule out exposure to the substance. ${ }^{2}$

Due to all of these factors, a urine toxicology screen should only be part of the overall picture. The clinical assessment of the patient and knowledge of signs and symptoms associated with ingestion of certain substances should be the basis for clinical decisionmaking and should take precedent over urine drug screening results. ${ }^{3}$
When might a urine toxicology screen be used? Neonatal use

In-utero toxin exposure, whether to recreational or prescribed drugs, can impact foetal development. This includes short-term effects such as neonatal abstinence syndrome and more long-term effects such as reduced growth, sudden infant death, and abnormal neurological and behavioural development. It is therefore important to identify neonates who are at risk from maternal toxin exposure. Self-reporting rates suggest that up to $10 \%$ of woman use illicit drugs in pregnancy, but screening gives higher estimates ${ }^{5}$

As maternal history may be unreliable, toxicology testing of the baby may be beneficial. Presence of drugs in the urine is particularly short lived in neonates, and only foetal exposure for 3-7 days (depending on the drug) before collection will be reflected. Therefore, a negative urine toxicology screen does not rule out maternal prenatal substance exposure. It is also worth noting that maternal labetalol use can give positive amphetamine results, thought to be due to crossreactivity with labetalol metabolites. ${ }^{6}$

If there has been intrapartum medical use of opioids, there can be concern about that causing a positive 
Table 1 Extent of urine toxicology detection for different classes of drugs. ${ }^{37}$

\begin{tabular}{|c|c|c|c|}
\hline Drug class & What is detected? & What is not detected? & Other considerations \\
\hline Amphetamines & $\begin{array}{l}\text { Most EIA detect D-amphetamine and D- } \\
\text { methamphetamine. }\end{array}$ & $\begin{array}{l}\text { Lack of sensitivity to } \\
\text { 3,4-methylenedioxyamphetamine (MDA) } \\
\text { and 3,4-methylenedioxyamphetamine } \\
\text { (MDMA, 'ecstasy'). }\end{array}$ & $\begin{array}{l}\text { Sensitivity for MDMA is about } 50 \% \\
\text { less than for D-amphetamine and D- } \\
\text { methamphetamine. } \\
\text { When screening neonates, maternal } \\
\text { labetalol use may give a positive result as } \\
\text { labetalol metabolites have been reported to } \\
\text { cause amphetamine positive screens. }\end{array}$ \\
\hline Benzodiazepines & $\begin{array}{l}\text { Most ElAs detect the diazepam metabolites } \\
\text { nordiazepam and/or oxazepam. }\end{array}$ & $\begin{array}{l}\text { Lorazepam, clonazepam and other } \\
\text { benzodiazepines do not share these } \\
\text { metabolites so are often undetected. }\end{array}$ & $\begin{array}{l}\text { Some benzodiazepines (particularly } \\
\text { clonazepam) at therapeutic or even above } \\
\text { therapeutic doses may not exceed detection } \\
\text { levels in the urine. }\end{array}$ \\
\hline Cocaine & $\begin{array}{l}\text { EIA detects benzoylecgonine (inactive } \\
\text { metabolite excreted in the urine) with good } \\
\text { sensitivity and specificity. } \\
\text { Coca tea and some other preparations } \\
\text { of the plant common in the Hispanic } \\
\text { population may produce positive results. }\end{array}$ & & $\begin{array}{l}\text { Passive inhalation (unless prolonged and } \\
\text { heavy exposure) will not produce a positive } \\
\text { result. } \\
\text { Acute massive overdose may take longer to } \\
\text { metabolise and so time for metabolite to } \\
\text { show up in the urine may be longer. }\end{array}$ \\
\hline Opiates & $\begin{array}{l}\text { ElAs target natural alkaloids including } \\
\text { morphine and codeine. As heroin } \\
\text { (diacetylmorphine) is directly synthesised } \\
\text { from morphine, this is often also picked up. }\end{array}$ & $\begin{array}{l}\text { Synthetic opioids such as methadone, } \\
\text { oxycodone, fentanyl and tramadol are } \\
\text { frequently undetected. They may require } \\
\text { adjunct immunoassays, which also have } \\
\text { cross reactivity. }\end{array}$ & $\begin{array}{l}\text { This may be the least sensitive and specific } \\
\text { urinary drug screen. }\end{array}$ \\
\hline Marijuana & $\begin{array}{l}\text { ElAs detect 11-nor-9-carboxy-delta-9- } \\
\text { tetrahydrocannabinol, which is the major } \\
\text { metabolite of marijuana excreted in the } \\
\text { urine. Generally good sensitivity and } \\
\text { specificity for this. }\end{array}$ & $\begin{array}{l}\text { Synthetic cannabinoids like 'spice' and } \\
\text { 'K2' not detected with most ElAs. }\end{array}$ & \\
\hline Lysergic acid diethylamide (LSD) & $\begin{array}{l}\text { High sensitivity but low specificity due to } \\
\text { the fact that only a small amount of the } \\
\text { parent molecule appears in the urine. }\end{array}$ & & $\begin{array}{l}\text { New generation immunoassays are } \\
\text { becoming available which targets the } \\
\text { metabolite 2-oxo-3-hydroxy-LSD, which } \\
\text { appears in greater concentrations in the } \\
\text { urine, so this may improve detectability. }\end{array}$ \\
\hline Tricyclic antidepressants (TCAs) & & & $\begin{array}{l}\text { There is a high overlap in structure between } \\
\text { TCAs and other agents such as muscle } \\
\text { relaxants, antipsychotics, anticonvulsants } \\
\text { and antihistamines, so there is a high } \\
\text { prevalence of inappropriate results. Not } \\
\text { recommended as the test used if TCA } \\
\text { toxicity is suspected. }\end{array}$ \\
\hline
\end{tabular}

EIAs, enzymatic immunoassays; TCA, tricyclic antidepressants.

opioid result on a neonatal urine toxicology screen. As discussed, synthetic opioids such as fentanyl and tramadol will not be detected and semi-synthetic opioids such as pethidine have variable cross-reactivity

\section{Box 1 Drugs/toxins not detected by routine urine} toxicology screening ${ }^{3}$

- Non-benzodiazepine hypnotics (zolpidem, zopiclone)

- Ketamine

- Mescaline (peyote)

- Psilocybin (magic mushrooms)

- Gamma-hydroxybutyrate (GHB)

1,4-Butanediol (precursor to GHB)

- Chloral hydrate

- Synthetic/designer cannabinoids ('spice' and 'K2')

- Tryptamines

- Phenethylamine derivatives (synthetic stimulants, 'bath salts', '2C' drugs)

- Imidazoline receptor agonists (clonidine, tetrahydrozoline, oxymetazoline) depending on the EIA. Therefore, a positive screen may not be related to medical opiate use, particularly if synthetic or semi-synthetic opiates were used. ${ }^{2}$

To screen for more chronic substance exposure, hair or meconium can be used; however, these tests are less widely available. Furthermore, if the first maternal substance exposure was very soon before delivery, it may not yet have been deposited in the meconium, therefore you may get a false negative. ${ }^{2}$

It has been demonstrated that in neonates, urine toxicology screening has a low yield. In one large study, urine screening did not pick up any non-medical drug use that was not picked up by meconium testing. However, the urine testing failed to detect a significant number of cases of non-medical drug use that were picked up by meconium analysis. ${ }^{6}$

Testing in altered consciousness

In paediatric patients presenting with Brief Resolved Unexplained Events (BRUE) (formally Apparent Life Threatening Episode [ALTE]) or altered consciousness, 


\begin{tabular}{|c|c|c|}
\hline Drug class & Drug & $\begin{array}{l}\text { Detection window } \\
\text { from last use (urine) }\end{array}$ \\
\hline \multirow[t]{3}{*}{ Amphetamines } & D-amphetamine & 3 days \\
\hline & D-methamphetamine & 3 days \\
\hline & MDMA & 2 days \\
\hline \multirow[t]{3}{*}{ Benzodiazepines } & Diazepam/nordiazepam & 10 days \\
\hline & Lorazepam & 5 days \\
\hline & Midazolam & 2 days \\
\hline \multirow[t]{2}{*}{ Cocaine } & Cocaine & $<1$ day \\
\hline & Benzoylecgonine (metabolite) & 5 days \\
\hline \multirow[t]{2}{*}{ Opiates } & Morphine & 3 days \\
\hline & Codeine & 3 days \\
\hline \multirow[t]{4}{*}{ Marijuana } & Occasional (1-2 times a week) & 3 days \\
\hline & Moderate (4-6 times a week) & 5 days \\
\hline & Heavy (daily use) & 10 days \\
\hline & Chronic daily use & 30 days \\
\hline \multirow[t]{2}{*}{ LSD } & LSD & $<1$ day \\
\hline & $\begin{array}{l}\text { 2-0xo-3-hydroxy-LSD } \\
\text { (metabolite) }\end{array}$ & 5 days \\
\hline
\end{tabular}

LSD, lysergic acid diethylamide; MDMA, 3,4-methylenedioxyamphetamine.

it is important to consider a toxicological cause, particularly given how prevalent toxin exposure is in this population. $^{2}$

In one study looking at patients under two presenting with ALTEs, $8.4 \%$ had a positive urine toxicology screen that could demonstrate a possible cause. They therefore suggested that this was a routine part of investigations in an ALTE presentation. ${ }^{7}$ Similar findings have been replicated in other studies, which have also highlighted that urine toxicology screens were useful in picking up toxins as a cause of apnoea. ${ }^{8}$

In line with this, the Royal College of Paediatrics and Child Health guideline in managing children and young people with an acute decrease in conscious level suggested that $10 \mathrm{~mL}$ of urine be collected and saved for later analysis, including urine toxicology. ${ }^{9}$

Use in intoxication and in the teenage population

Recreational drug use in teenagers is an underrecognised cause of mortality and morbidity and those who start using recreational drugs during childhood, have a much higher risk of dependence. It is tempting to want to detect recreational drug use in order to raise the issue with young people; however, there is little evidence that positive urine toxicology tests have any bearing on reduction of recreational drug use in adolescents. $^{10}$

In one study looking at urine toxicology screens performed in paediatric emergency department (ED), $7 \%$ gave an unexpectedly positive result. However, only in $1 \%$ did this lead to a change in management, and all of these cases had signs and/or symptoms consistent with the drug that had been ingested. ${ }^{11}$ Thus, they concluded that generally speaking urine

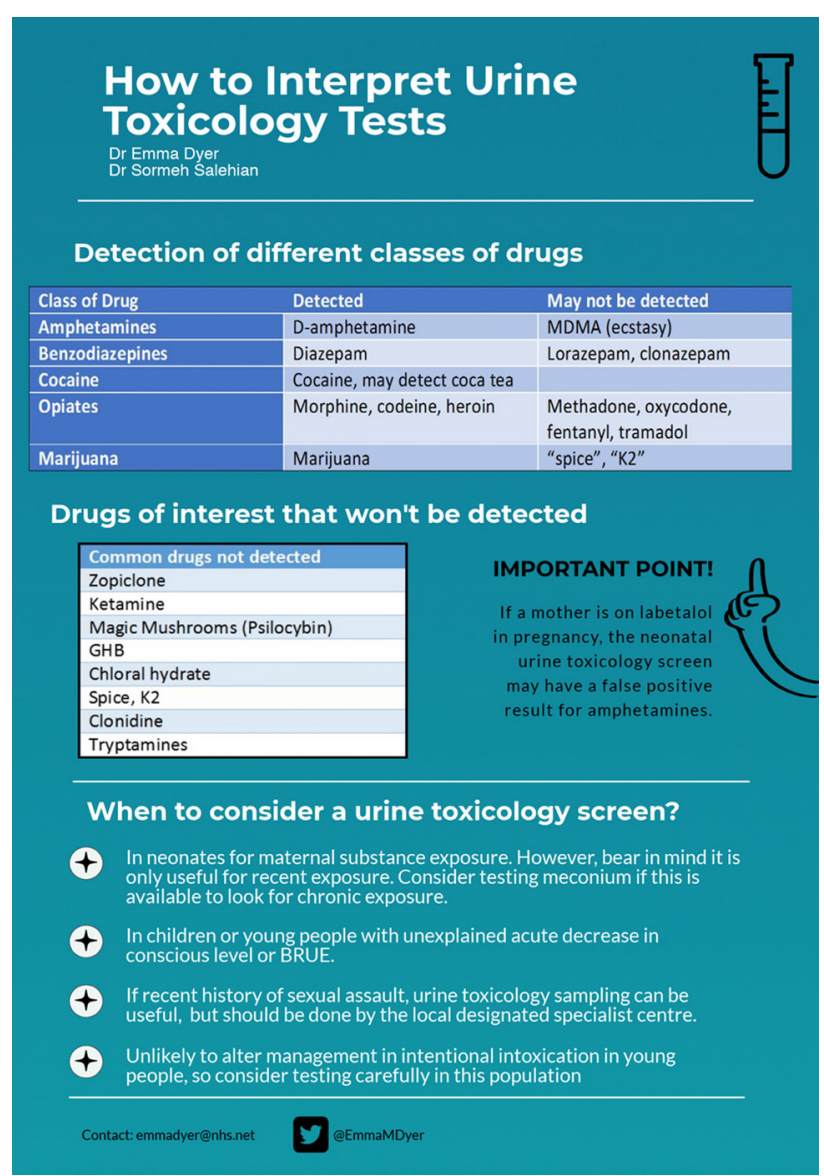

Figure 2 Summary infographic. GHB, gamma-hydroxybutyrate; MDMA, 3,4-methylenedioxyamphetamine.

toxicology screening rarely alters management and we should think carefully before testing this in ED.

\section{Use in safeguarding/assault cases}

In sexual assault cases, alcohol or drug use immediately before the event is reported in over $40 \%$ of adolescent victims and adolescent perpetrators. This may be coincidental due to recreational drug use being common in adolescents, but if drug facilitated sexual assault is suspected, it can be important to establish the substance involved. ${ }^{12}$ In the UK, the faculty of forensic and legal medicine recommends that when doing a forensic examination following a sexual assault, a urine sample to test for drugs and/or alcohol be obtained if the incident happened within the preceding 5 days. If it occurred over 3 days ago, they recommend that hair is also taken for testing due to rapid clearance from the urine. ${ }^{13}$

Some relevant drugs will not show up on the screen. It is important to be aware of the implications of positive and negative drug screens so as not to mislead the healthcare and/or litigation teams in these cases. Particularly with a negative screen as that does not rule out the use of drugs to sedate the victim. ${ }^{3}$

It is important to note that in the UK these examinations are not usually carried out by general 
paediatricians, and best practice is to refer patients within an hour of disclosure to the local specialist unit, who can collect forensic samples as required. ${ }^{14}$

For a summary of the article, see figure 2 .

\section{CLINICAL BOTTOM LINE}

1. Point of care urine toxicology testing is quick, inexpensive and simple to do.

2. A negative result does not indicate absence of substance and clinical judgement takes priority.

3. Be aware of false positives in neonates where mother has been taking labetalol.

4. Consider urine toxicology for all cases of altered consciousness.

5. Urine toxicology testing is useful is cases of sexual assault, but sample collection should be done by specialist centres rather than general paediatricians.

Contributors EMD was responsible for all aspects of this work including the outline and content of the manuscript and design of the infographic. SS critically appraised the manuscript and contributed further ideas. All authors edited the manuscript and agree to be accountable for all aspects of the work.

Funding The authors have not declared a specific grant for this research from any funding agency in the public, commercial or not-for-profit sectors.

Competing interests None declared.

Patient consent for publication Not required.

Provenance and peer review Commissioned; externally peer reviewed.

\section{REFERENCES}

1 Gummin DD, Mowry JB, Spyker DA, et al. 2016 Annual Report of the American Association of Poison Control Centers' National Poison Data System (NPDS): 34th annual report. Clin Toxicol 2017;55:1072-254.

2 Archer JR, Wood DM, Dargan PI. How to use toxicology screening tests. Arch Dis Child Educ Pract Ed 2012;97:194-9.
3 Nelson ZJ, Stellpflug SJ, Engebretsen KM. What can a urine drug screening immunoassay really tell us? J Pharm Pract 2016;29:516-26.

4 Macfarlane PI, Ellis R, Hughes C, et al. Urine collection pads: are samples reliable for urine biochemistry and microscopy? Pediatr Nephrol 2005;20:170-9.

5 Farst KJ, Valentine JL, Hall RW. Drug testing for newborn exposure to illicit substances in pregnancy: pitfalls and pearls. Int J Pediatr 2011;2011:1-7.

6 Wood KE, Sinclair LL, Rysgaard CD, et al. Retrospective analysis of the diagnostic yield of newborn drug testing. BMC Pregnancy Childbirth 2014;14:250.

7 Pitetti RD, Whitman E, Zaylor A. Accidental and nonaccidental poisonings as a cause of apparent lifethreatening events in infants. Pediatrics 2008;122:e359-62.

8 Davies F, Gupta R. Apparent life threatening events in infants presenting to an emergency department. Emerg Med J 2002;19:11-16.

9 Reynolds S, Marikar D, Roland D. Management of children and young people with an acute decrease in conscious level (RCPCH guideline update 2015). Arch Dis Child Educ Pract Ed 2018;103:146-51.

10 Levy S, Siqueira LM, Ammerman SD, et al. Testing for drugs of abuse in children and adolescents. Pediatrics 2014;133:e1798807.

11 Sugarman JM, Rodgers GC, Paul RI. Utility of toxicology screening in a pediatric emergency department. Pediatr Emerg Care 1997;13:194-7.

12 Crawford-Jakubiak JE, Alderman EM, Leventhal JM. Care of the adolescent after an acute sexual assault. Pediatrics 2017; 139:e20164243.

13. Stark M. 2018. Recommendations for the collection of forensic specimens from complainants and suspect: Faculty of Forensic \& Legal Medicine.

$14 \mathrm{RCPCH}$. Service specification for the clinical evaluation of children and young people who may have been sexually abused: Royal College of Paediatrics and Child Health, 2015. 